\title{
Meta-analysis of the prognostic value of abnormally expressed IncRNAs in hepatocellular carcinoma
}

This article was published in the following Dove Press journal:

OncoTargets and Therapy

18 August 2016

Number of times this article has been viewed

\author{
Zhen $\mathrm{Qu}^{1, *}$ \\ Chun-Hui Yuan ${ }^{2, *}$ \\ Chang-Qing Yin' \\ Qing Guan² \\ Hao Chen' \\ Fu-Bing Wang' \\ 'Department of Laboratory \\ Medicine and Center for Gene \\ Diagnosis, Zhongnan Hospital of \\ Wuhan University, ${ }^{2}$ Department of \\ Immunology, School of Basic Medical \\ Sciences, Wuhan University, Wuhan, \\ People's Republic of China \\ *These authors contributed equally \\ to this work
}

Correspondence: Fu-Bing Wang Department of Laboratory Medicine and Center for Gene Diagnosis, Zhongnan Hospital of Wuhan University, No 169 Donghu Road, Wuchang District, Wuhan 43007I, People's Republic of China

Tel +862767813517

Fax +8627678I3128

Email wfb20042002@sina.com
Abstract: Many long noncoding RNAs (lncRNAs) have been reported to be abnormally expressed in hepatocellular carcinoma (HCC), and may have the potential to serve as prognostic markers. In this study, a meta-analysis was conducted to systematically evaluate the prognostic value of various lncRNAs in HCC. Eligible literatures were systematically collected from PubMed, Embase, Web of Science, and Cochrane Library (up to December 30, 2015). The main outcomes including overall survival, relapse-free survival, and disease-free survival were analyzed. Pooled hazard ratios (HRs) and 95\% confidence intervals (95\% CIs) were calculated using random- or fixed-effects models. A total of 2,991 patients with HCC in People's Republic of China from 27 studies were included in the analysis. The level of lncRNAs showed a significant association with clinical outcomes. Abnormally elevated lncRNA transcription level predicted poor overall survival (HR: 1.68, 95\% CI: 1.20-2.34, $\left.P=0.002 ; I^{2}=75.5 \%, P=0.000\right)$ and relapse-free survival (HR: 2.08, 95\% CI: 1.65-2.61, $\left.P<0.001 ; P^{2}=24.0 \%, P=0.215\right)$, while no association was observed with disease-free survival of HCC patients (HR: $1.39,95 \%$ CI: $0.51-3.78, P=0.524 ; I^{2}=81.3 \%, P=0.005$ ). Subgroup analysis further showed that lncRNA transcription level was significantly associated with tumor size (relative risk [RR]: $1.19,95 \% \mathrm{CI}: 1.01-1.39, P=0.035$ ), microvascular invasion (RR: $1.44,95 \% \mathrm{CI}: 1.10-1.89, P=0.009$ ), and portal vein tumor thrombus (RR: $1.50,95 \% \mathrm{CI}$ : 1.03-2.20, $P=0.036$ ). Publication bias and sensitivity analysis further confirmed the stability of our results. Our present meta-analysis indicates that abnormal lncRNA transcription level may serve as a promising indicator for prognostic evaluation of patients with HCC in People's Republic of China.

Keywords: lncRNA, HCC, survival, prognosis, meta-analysis

\section{Introduction}

Hepatocellular carcinoma (HCC) is the sixth most common cancer worldwide, and accounts for more than $80 \%$ of primary liver cancers. ${ }^{1}$ With advances in surgical techniques and the development of molecular target drugs, therapeutic approaches for the treatment of HCC now can be classified into three categories: potentially curative, palliative, and symptomatic. ${ }^{2,3}$ However, owing to the clinical characteristics of HCC, like insidious onset, high degree of malignancy, and nonspecific symptoms in early stage, the prognosis of HCC remains dismal with a 5-year overall survival (OS) rate of $0 \%-10 \%$ for the reason of late detection, and HCC ranks as the second leading cause of cancer-related deaths worldwide ( $\sim 745,553$ deaths in $2012,9.1 \%$ of all cancers). Thus, the outcome of HCC patients predominantly depends on early diagnosis and a timely therapeutic treatment. As a classic biomarker for HCC diagnosis, alfa-fetoprotein 
(AFP) is the widely used molecular marker for clinical HCC diagnosis; however, it often shows a false-positive result during pregnancy, as well as active liver disease, embryonic tumors, and certain gastrointestinal tumors. ${ }^{46}$ Therefore, the identification of more sensitive and specific biomarkers for early detection of HCC is desirable and urgently needed.

During the past decades of RNA biology study, long noncoding RNAs (lncRNAs) have emerged as an essential regulator in almost all aspects of biology. ${ }^{7}$ More importantly, accumulating evidence has demonstrated that multiple lncRNAs play an important role in tumorigenesis, ${ }^{8}$ and their abnormal expression confers tumor initiation, cancer cell growth, and metastasis during the development of HCC, ${ }^{9-11}$ For example, the abnormal expression of lncRNA MALAT1 and lncRNA, activated by tumor growth factor- $\beta$ (lncRNA-ATB), induced EMT and cell invasion and promoted the colonization of disseminated HCC cells. ${ }^{7,12,13}$ IncRNA-HEIH, as identified by microarray analysis in HCC samples, plays an oncogenic role in HCC development, which promotes in vivo tumor growth by regulating cell cycle of tumor cells. ${ }^{14}$

In patients with HCC, correlation analysis has further emphasized the potential of IncRNAs to be used as diagnostic or prognostic markers. High expressions of lncRNA-ATB and MALAT1 can be used as robust early prognostic indicators, which suggest a poor survival of HCC patients. ${ }^{12,13}$ The expression level of lncRNA-HEIH in hepatitis B virus (HBV)-related HCC is significantly associated with recurrence and is an independent prognostic factor for patient's survival. ${ }^{14}$ Using lncRNA microarrays, it has also been found that the IncRNA ZEB1-AS1 is frequently upregulated in HCC samples, especially in metastatic tumor tissues. Patients with ZEB1-AS1 hypomethylation (a tumor-specific ZEB1-AS1 promoter hypomethylation) or with high ZEB1-AS1 expression have poor recurrencefree survival (RFS).

Multiple lncRNAs, including ATB, MALAT1, HOTAIR, HEIH, ZEB1-AS1, MVIH, and GAS5,,$^{11,12,14-25}$ have been confirmed to be promising prognostic indicators for HCC. Among these lncRNAs, MALAT1 and HOTAIR have been comprehensively investigated in different tumors and the prognostic value of these two lncRNAs has been confirmed by systematic reviews using meta-analyses. ${ }^{26-28}$ With the aim to gain a better insight into the prognostic value of lncRNAs in patients with HCC, we conducted a systematic review of the published articles followed by a metaanalysis to evaluate the prognostic value of these aberrantly expressed lncRNAs.

\section{Materials and methods Search strategy}

The present review was performed in accordance with the standard guidelines for meta-analyses and systematic reviews of tumor marker studies. ${ }^{29,30}$ The research databases PubMed, Embase, Cochrane Library, and Web of Science were independently used by two authors (Zhen Qu and Chun-Hui Yuan) to obtain all relevant articles about the prognostic value of IncRNA in HCC. The literature search ended in December 30, 2015. The search strategy used both $\mathrm{MeSH}$ terms and free-text words to increase the sensitivity of the search. The following search terms were used: ("Long noncoding RNA", "IncRNA", "LincRNA", "Long ncRNA", "Long intergenic non-coding RNA") AND ("hepatocellular cancer", "hepatocellular tumor", "hepatocellular carcinoma", "Hepatocellular neoplasm", "Hepatocellular neoplasm", "liver cancer", "liver tumor", "liver carcinoma", "liver neoplasm", "HCC"). All included studies were retrieved in English database together with relevant references and manual searches to implement our search.

\section{Eligibility criteria}

Studies were considered eligible if they met the following criteria: patients were pathologically diagnosed with HCC, regardless of tumor-node-metastasis (TNM) stage; the expression of LncRNAs was determined in tissues from patients with HCC using quantitative reverse transcriptionpolymerase chain reaction or microarray analysis, including tumor or adjacent tissues; the prognostic value of one lncRNA was investigated; the relationship between lncRNA expression and survival (OS, relapse-free survival, and disease-free survival [DFS]) was examined; and sufficient data were provided to estimate hazard ratios (HRs) for survival rates and their $95 \%$ confidence interval $(95 \% \mathrm{CI})$. If data subsets were published in more than one article, only the most recent one was included, and if sample population consisted of less than 20 cases, the study was excluded. The studies were restricted to human experiments, and single case reports or animal studies were excluded. All eligible studies were carefully assessed by the same two authors, and discrepancies were resolved through discussion with a third reviewer (Fu-Bing Wang).

\section{Data quality assessment and extraction}

Quality assessment was performed independently by three authors (Zhen Qu, Chun-Hui Yuan, and Fu-Bing Wang). All eligible studies were scored as our previously described method $^{31}$ and summarized in Table 1. Data was extracted 


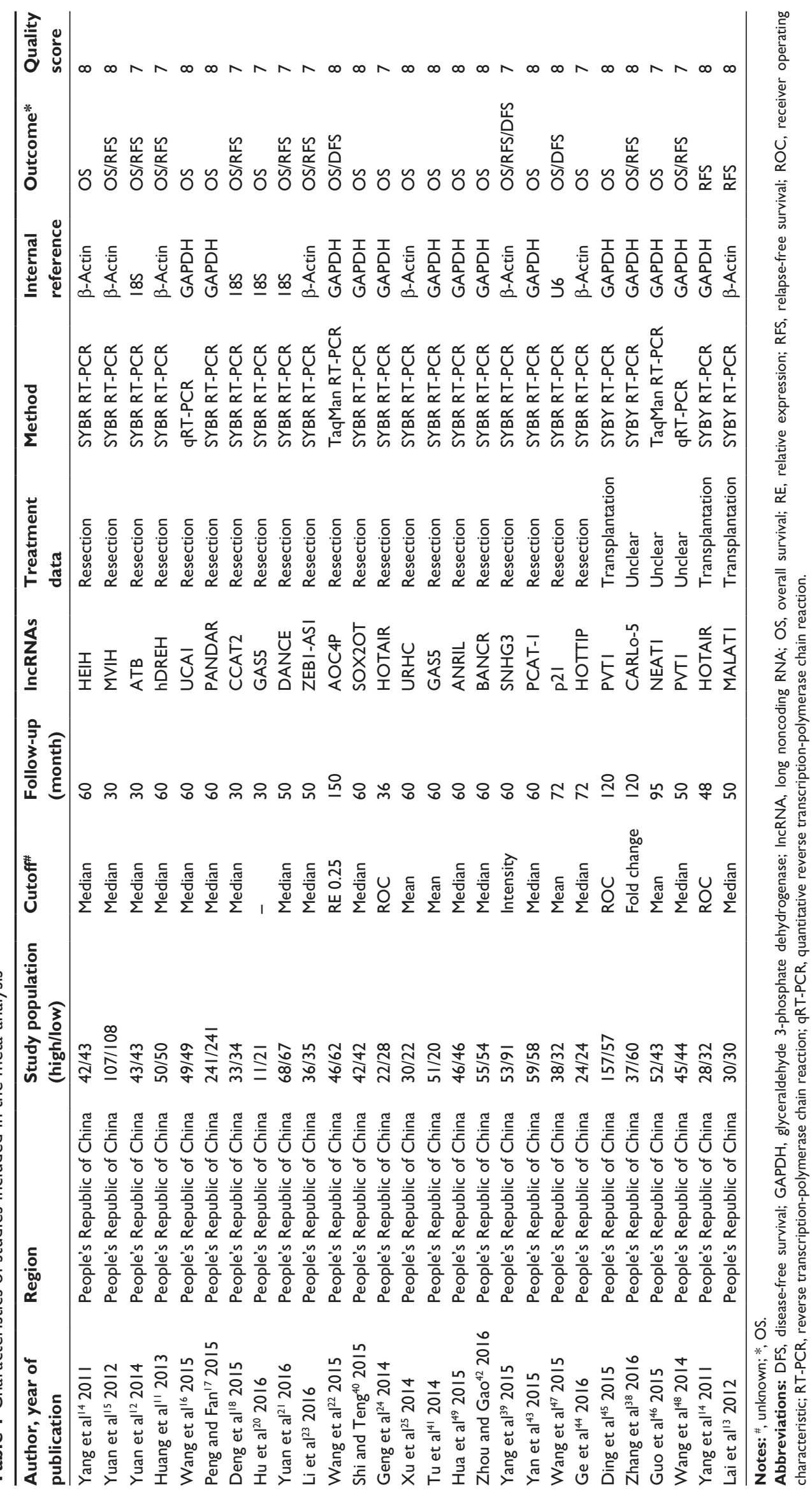


independently by two authors (Zhen Qu and Chun-Hui Yuan) and they reached a consensus on all items. For each eligible study, the following information was collected: the first author, journal name, year of publication, and characteristics of the study population (including the country of the population enrolled, publication year, sample size, age, sex, stage, histological differentiation, follow-up, detective methods and items, cutoff values, and treatment data) (Table 1). Time-toevent data, which were used to reveal survival rate (KaplanMeier curve), were extracted to calculate the corresponding HR as per previously described methods. ${ }^{31-34}$

\section{Statistical software analysis}

Statistical analysis was performed with Stata statistical software package, version 13.0 (StataCorp LP, College Station, TX, USA), and $P$-value less than 0.05 was considered statistically significant. Statistical heterogeneity among studies was assessed using the $I^{2}$ statistic, with significant heterogeneity defined as $I^{2}>50 \% .{ }^{35}$ Potential causes of heterogeneity were explored by meta-regression analyses. Pooled HRs and their associated 95\% CIs were estimated using a fixed-effect model (Mantel-Haenszel), while the random-effects model was performed to summarize the statistical indicators when significant heterogeneity was present. We also conducted a one-way sensitivity analysis to evaluate the stability of the results. Publication bias was evaluated using the funnel plot with Begg's test and Egger's test. ${ }^{31}$

\section{Results Eligible studies and characteristics}

As shown in the flow diagram (Figure 1), we retrieved 806 articles from four databases. After the titles and abstracts were reviewed, 734 irrelevant or duplicate articles were excluded. A total of 72 articles were further reviewed in detail. In all, 42 articles were excluded because of no survival data to estimate HR for further analysis; three articles that reported the prognostic value of multiple lncRNAs were also excluded. ${ }^{19,36,37}$ As a result, 27 published articles were included in the current meta-analysis. ${ }^{11-18,20-25,38-50}$ Table 1 summarizes the main characteristics of the included studies. OS, RFS, and DFS were estimated as survival outcome measures in $92.6 \%$ $(25 / 27),{ }^{11,12,15-18,20-25,38-50} 40.7 \%(11 / 27),{ }^{11-15,18,21,23,45,47,48}$ and $11.1 \%(3 / 27)^{22,38,39}$ of the studies, respectively.

\section{Global analysis between IncRNA transcription level and HCC survival}

A total of 25 studies reported OS of HCC based on different expressions of lncRNAs in 2,871 patients. We extracted HRs and their associated 95\% CIs of OS from the included studies, HR $>1$ implies a poor prognosis. ${ }^{31}$ The estimated pooled HR for all studies showed a significant association between lncRNA transcription level and OS in HCC patients (HR: 1.68, 95\% CI: $1.20-2.34, P=0.002$, random effects) (Figure 2A), while a significant heterogeneity existed between studies $\left(I^{2}=75.5 \%, P=0.000\right)$.

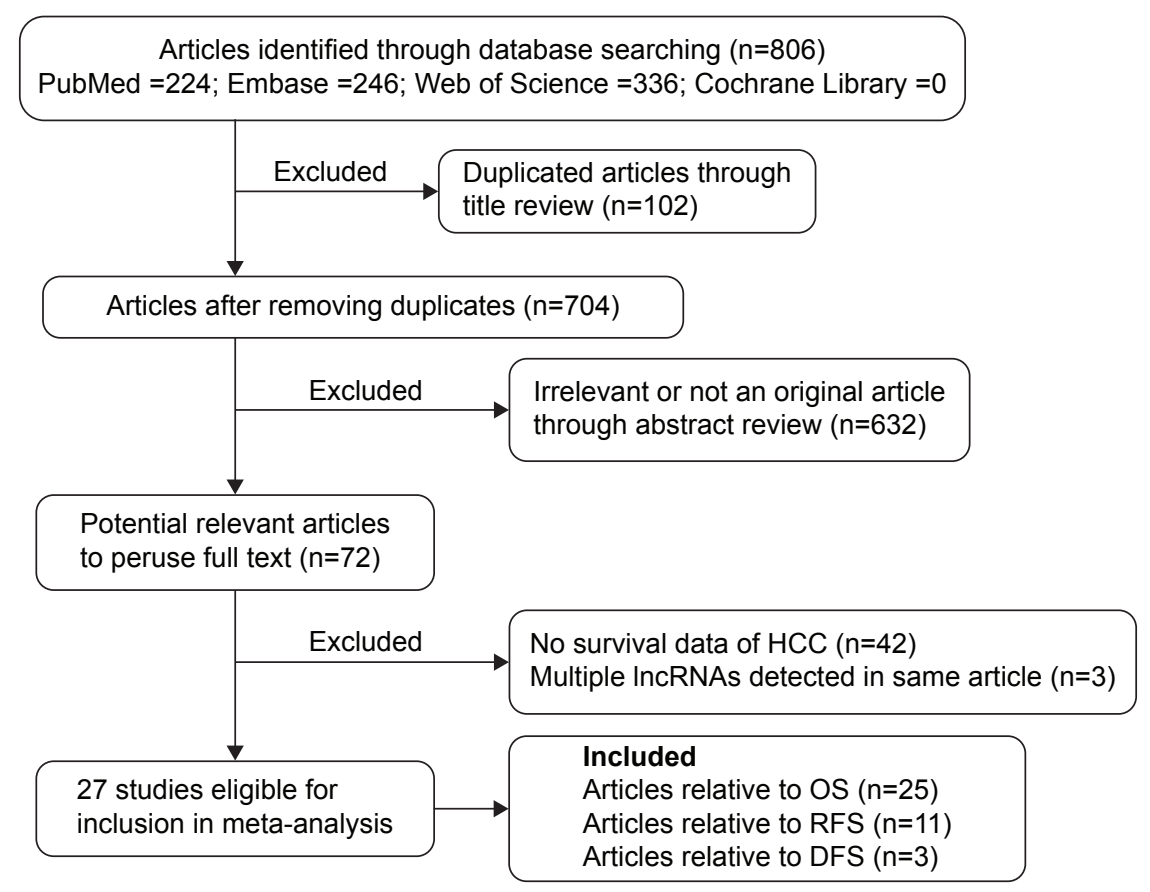

Figure I Flowchart of the strategy used for the selection of reports used in our analysis.

Abbreviations: DFS, disease-free survival; HCC, hepatocellular carcinoma; IncRNAs, long noncoding RNAs; OS, overall survival; RFS, relapse-free survival. 


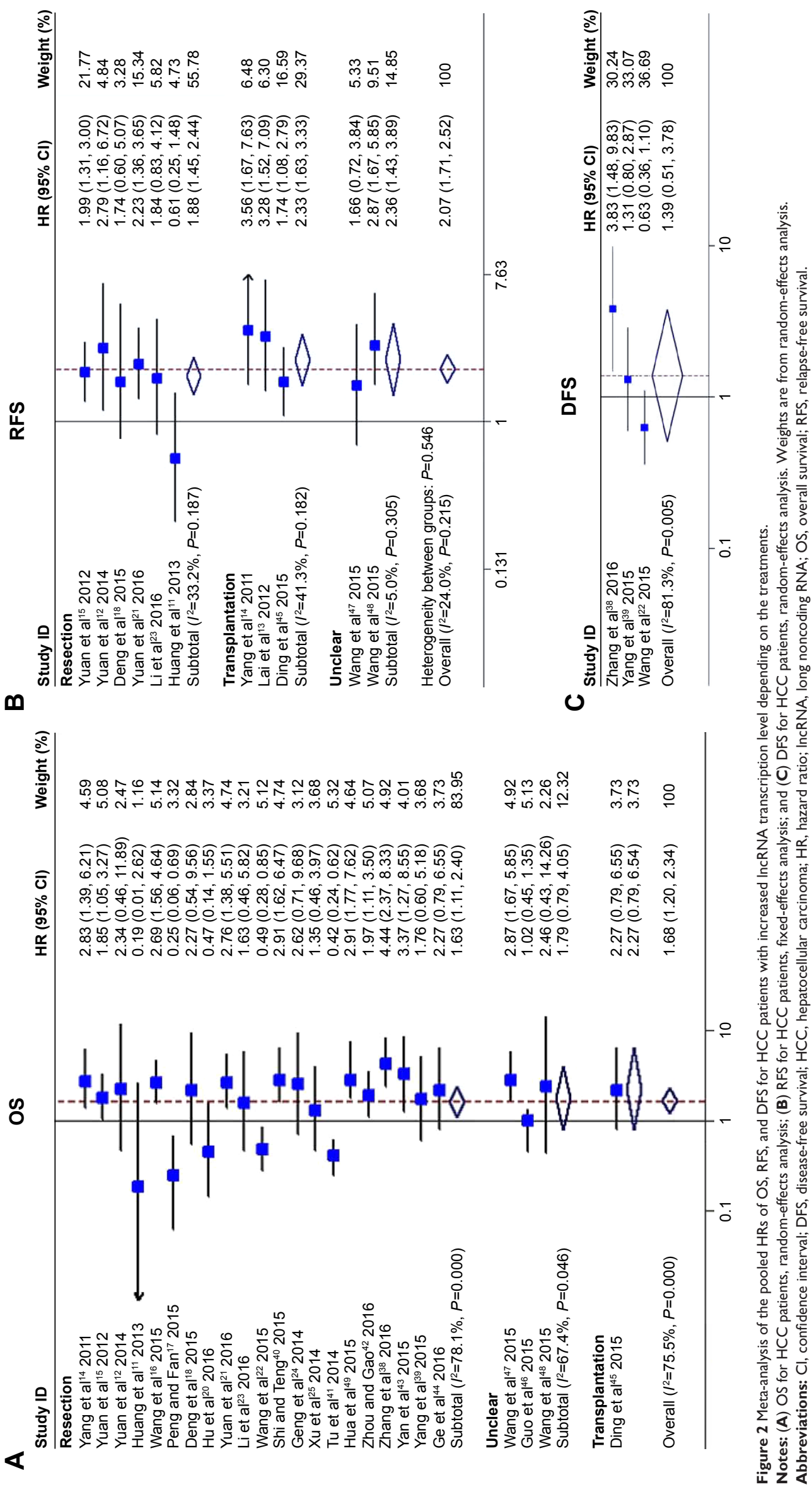


Due to the presence of heterogeneity, subgroups were analyzed based on treatment of HCC, including hepatic resection and liver transplantation, as well as unclear treatment. We detected a significant association between HOTAIR and OS of HCC patients with hepatic resection (HR: 1.63, 95\% CI: $1.11-2.40, P=0.013$ ), but not in those who received unclear treatment (HR: $1.79,95 \%$ CI: $0.79-4.05, P=0.164$ ) or liver transplantation (HR: $2.27,95 \% \mathrm{CI}$ : $0.79-6.54, P=0.129$ ) (Figure 2A). Significant heterogeneity existed across studies in the subgroup of hepatic resection, and moderate heterogeneity in the subgroups of unclear treatment. Due to the limited number of included articles about liver transplantation, the heterogeneity in this subgroup could not be calculated. Thus, we speculated that the treatment of HCC alters the predictive value of IncRNA transcription level in OS.

To explore potential sources of heterogeneity for OS, we conducted meta-regression considering following covariates: age, sex, detective method, cutoff, follow-up, HBV infection, treatment, tumor size, tumor number, AFP level, cirrhosis, TNM stage, invasion, and histological differentiation to quantify the heterogeneity. As was found in univariate analysis, no significant inter-study heterogeneity was found in these covariates $(P>0.05$, Figure S1). For meta-analysis of the association between IncRNA transcription level and OS, the funnel plot was symmetrical; Begg's test $(P=0.148)$ and Egger's test $(P=0.672)$ (Figure S2) showed no significant publication bias across studies. Sensitivity analysis showed that neither the direction nor the magnitude of the estimated pooled results for OS was obviously affected, indicating that no single study dominated our results (Figure S3A), which further confirmed the stability of our results.

The prognostic significance of lncRNAs in RFS and DFS was evaluated in eleven studies ${ }^{11-15,18,21,23,45,47,48}$ with 1,193 patients and in three studies ${ }^{22,38,39}$ with 322 patients, respectively (Table 1). IncRNA transcription level was significantly associated with RFS (HR: 2.08 , 95\% CI: $1.65-2.61, P=0.000)$ with no significant heterogeneity $\left(I^{2}=24.0 \%, P=0.215\right)$ (Figure 2B). Sensitivity analysis was not changed after omitting any of the included studies in RFS (Figure S3B). However, it showed that high lncRNA transcription level was not associated with DFS in HCC (HR: $1.39,95 \%$ CI: $0.51-3.78, P=0.524)$ with obvious heterogeneity $\left(I^{2}=81.3 \%, P=0.005\right)$ (Figure 2C). Metaregression analysis, sensitivity analysis, and assessment of publication bias were not performed due to the relatively little heterogeneity across studies or limited number of included articles.

\section{Correlation of IncRNAs with clinicopathological characteristics of HCC}

The association between lncRNAs and clinicopathological characteristics was analyzed with relative risk (RR); RR $>1$ implied that lncRNA was associated with parameter. In HCC, high lncRNA transcription level was significantly associated with tumor size ( $>5 \mathrm{~cm}$ vs $\leq 5 \mathrm{~cm}$ : RR $=1.19,95 \%$ CI: $1.01-1.39, P=0.035$ ), microvascular invasion (Yes vs No: $R R=1.44,95 \%$ CI: $1.10-1.89, P=0.009)$, and portal vein tumor thrombus (Yes vs No: $R R=1.5095 \%$ CI: $1.03-2.20$, $P=0.036$ ). However, no significant correlation was found with HBV infection (HBV surface antigen positive vs negative: $R R=0.83,95 \%$ CI: $0.67-1.03$ ), cirrhosis (Yes vs No: RR $=0.94,95 \%$ CI: 0.67-1.32), and TNM stage (III/IV vs I/II: RR $=1.11,95 \%$ CI: $0.79-1.56$ ), as well as other characteristics like sex, AFP level, tumor number, and histological differentiation (Table 2).

\section{Discussion}

Up to now, the treatments for $\mathrm{HCC}$ are still limited, and most of them are only available to the early stage. In the later stages, traditional chemotherapy has only marginal effects and may accompany with serious side effects. Thus, novel molecular markers that can help in early diagnosis and prognosis evaluation are still urgently needed. ${ }^{7}$ In recent years, numerous studies have demonstrated that lncRNAs are involved in various biological processes, including cancer progression and metastasis. ${ }^{51}$ More importantly, aberrant expression of multiple lncRNAs was found to be involved in the tumorigenesis and may have prognostic potential of HCC.

In this meta-analysis, we examined the prognostic role of these lncRNAs in HCC and the relation between lncRNAs and clinicopathological characteristics. Meta-regression analysis and sensitivity analysis were performed in the current study, as well as subgroup analysis in a fixed or random model, which enhanced the statistical power to confirm the prognostic potential of these lncRNAs in HCC. A total of 27 studies comprising 25 lncRNAs and 2,991 patients were included into this meta-analysis. Pooled data analyses confirmed that high lncRNA transcription level represents a significant risk factor for both OS (HR: $1.68,95 \% \mathrm{CI}$ : $1.20-2.34, P=0.002$ ) and RFS (HR: $2.08,95 \%$ CI: $1.65-2.61$, $P=0.000$ ), and significantly increased risk for death and disease recurrence. As a significant heterogeneity $\left(I^{2}=75.5 \%\right.$, $P<0.001$ ) was observed between studies in OS analysis, we then conducted subgroup and meta-regression analyses to quantify the heterogeneity. In subgroup analysis, different 
Table 2 Risk estimates of the association between high level of IncRNAs and clinicopathologic characteristics of HCC

\begin{tabular}{|c|c|c|c|c|c|c|c|}
\hline \multirow[t]{2}{*}{ Items } & \multirow[t]{2}{*}{$\begin{array}{l}\text { Number } \\
\text { of studies }\end{array}$} & \multirow{2}{*}{$\begin{array}{l}\text { Relative risk of } \\
\text { higher IncRNAs } \\
\text { OR }(95 \% \mathrm{CI})\end{array}$} & \multicolumn{2}{|c|}{$\begin{array}{l}\text { Significant } \\
\text { test }\end{array}$} & \multicolumn{2}{|c|}{$\begin{array}{l}\text { Heterogeneity } \\
\text { test }\end{array}$} & \multirow[t]{2}{*}{ References } \\
\hline & & & $\bar{Z}$ & $P$-value & $P^{2}$ & $P$-value & \\
\hline $\begin{array}{l}\text { Sex } \\
\text { (male vs female) }\end{array}$ & 19 & $0.99(0.94,1.040)$ & 0.47 & 0.635 & $50.00 \%$ & 0.005 & $\begin{array}{l}\text { Huang et al, }{ }^{11} \text { Lai et al }{ }^{13} \text { Yang et all, }{ }^{14} \text { Wang et al, }{ }^{16} \\
\text { Peng et al, }{ }^{17} \text { Deng et al, }{ }^{18} \text { Hu et al, }{ }^{20} \text { Yuan et al, },{ }^{21} \\
\text { Wang et al, },{ }^{22} \text { Li et all, }{ }^{23} \text { Xu et al, }{ }^{25} \text { Zhang et al, }{ }^{38} \text { Yang } \\
\text { et al },^{39} \text { Shi et al, }{ }^{40} \text { Tu et al, }{ }^{41} \text { Yan et al, }{ }^{43} \text { Ding et al, }{ }^{45} \\
\text { Wang et al, },{ }^{47} \text { Wang et al }{ }^{48}\end{array}$ \\
\hline $\begin{array}{l}\text { Tumor size } \\
(>5 \mathrm{~cm} \text { vs } \leq 5 \mathrm{~cm})\end{array}$ & 17 & 1.19 (1.01, I.39) & 2.11 & 0.035 & $64.00 \%$ & 0 & 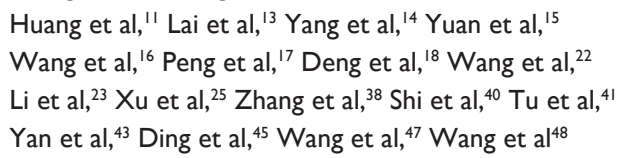 \\
\hline $\begin{array}{l}\text { Tumor number } \\
\text { (multi vs single) }\end{array}$ & 15 & I.II $(0.93,1.32)$ & 1.19 & 0.235 & $59.40 \%$ & 0.002 & $\begin{array}{l}\text { Huang et al, }{ }^{11} \text { Lai et al, }{ }^{13} \text { Yuan et al, }{ }^{15} \text { Peng et al, }{ }^{17} \\
\text { Hu et al, }{ }^{20} \text { Wang et al, }{ }^{22} \text { Li et al }{ }^{23} \text { Xu et al, }{ }^{25} \text { Zhang } \\
\text { et al }{ }^{38} \text { Yang et all, }{ }^{39} \text { Tu et al, }{ }^{41} \text { Yan et al, }{ }^{43} \text { Ding et al, }{ }^{45} \\
\text { Wang et al, }{ }^{47} \text { Wang et al }{ }^{48}\end{array}$ \\
\hline $\begin{array}{l}\text { Cirrhosis } \\
\text { (yes vs no) }\end{array}$ & 12 & $0.94(0.67,1.32)$ & 0.36 & 0.718 & $94.30 \%$ & 0 & $\begin{array}{l}\text { Huang et al, }{ }^{11} \text { Yang et al, }{ }^{14} \text { Yuan et al, }{ }^{15} \text { Wang et al, }{ }^{16} \\
\text { Peng et al, }{ }^{17} \text { Hu et al, }{ }^{20} \text { Zhang et al, }{ }^{38} \text { Shi et al },{ }^{40} \\
\text { Yan et al, }{ }^{43} \text { Ding et al, }{ }^{45} \text { Wang et al, },{ }^{47} \text { Wang et al }{ }^{48}\end{array}$ \\
\hline \multicolumn{8}{|l|}{ AFP level (ng/mL) } \\
\hline$>20$ vs $\leq 20$ & 11 & $1.19(0.93,1.53)$ & 1.41 & 0.158 & $88.70 \%$ & 0 & $\begin{array}{l}\text { Huang et al, }{ }^{11} \text { Yuan et al, }{ }^{15} \text { Wang et al, }{ }^{16} \text { Peng et al, }{ }^{17} \\
\text { Deng et al }{ }^{18} \text { Wang et al, }{ }^{22} \text { Li et al, },^{23} \text { Tu et al, }{ }^{41} \\
\text { Yan et al, }{ }^{43} \text { Wang et al }{ }^{48}\end{array}$ \\
\hline$>400$ vs $\leq 400$ & 6 & $\mathrm{I} .07(0.87, \mathrm{I} .30)$ & 0.63 & 0.529 & $34.40 \%$ & 0.178 & $\begin{array}{l}\text { Lai et al, }{ }^{13} \text { Yang et al, }{ }^{14} \mathrm{Xu} \text { et al, }{ }^{25} \text { Ding et } a l,{ }^{45} \\
\text { Wang et a }{ }^{47}\end{array}$ \\
\hline \multicolumn{8}{|l|}{ Age (years) } \\
\hline$>50$ vs $\leq 50$ & 7 & $0.88(0.71,1.08)$ & 1.25 & 0.211 & $12.80 \%$ & 0.333 & Lai et al, ${ }^{13} \mathrm{Hu}$ et al, ${ }^{20} \mathrm{Xu}$ et al, ${ }^{25}$ Shi et al, ${ }^{40}$ Yan et al ${ }^{143}$ \\
\hline$>55$ vs $\leq 55$ & 8 & $1.00(0.87,1.15)$ & 0.03 & 0.972 & $0.00 \%$ & 0.457 & $\begin{array}{l}\text { Huang et al, }{ }^{11} \text { Yuan et al, }{ }^{15} \text { Wang et al, }{ }^{16} \text { Deng et al, }{ }^{18} \\
\text { Wang et al, }{ }^{22} \text { Li et al, }{ }^{23} \text { Zhang et al, }{ }^{38} \text { Wang et a al }{ }^{48}\end{array}$ \\
\hline$>60$ vs $\leq 60$ & 4 & $\mathrm{I} .10(0.89, \mathrm{I} .36)$ & 0.92 & 0.355 & $0.00 \%$ & 0.986 & Yang et al, ${ }^{14}$ Peng et al, ${ }^{17}$ Ding et al, ${ }^{45}$ Wang et a ${ }^{47}$ \\
\hline TNM (III/IV vs I/II) & 12 & I.II $(0.79, I .56)$ & 0.62 & 0.538 & $92.80 \%$ & 0 & $\begin{array}{l}\text { Yang et al, }{ }^{14} \text { Yuan et al, }{ }^{15} \text { Wang et al, }{ }^{16} \text { Peng et al, }{ }^{17} \\
\text { Hu et al },{ }^{20} \text { Li et al, }{ }^{23} \mathrm{Xu} \text { et al, }{ }^{25} \text { Shi et al, }{ }^{40} \text { Tu et al, },{ }^{41} \\
\text { Yan et al, }{ }^{43} \text { Ding et al },{ }^{45} \text { Wang et al }{ }^{48}\end{array}$ \\
\hline $\begin{array}{l}\text { Histological } \\
\text { differentiation } \\
\text { (poor vs well) }\end{array}$ & 10 & $1.04(0.81,1.32)$ & 0.28 & 0.778 & $71.50 \%$ & 0 & $\begin{array}{l}\text { Huang et al, }{ }^{1} \text { Lai et al, }{ }^{13} \text { Yang et al, }{ }^{14} \text { Wang et al, }{ }^{16} \\
\text { Peng et al, }{ }^{17} \text { Wang et al, }{ }^{22} \text { Xu et al, }{ }^{25} \text { Shi et al, }{ }^{40} \\
\text { Yan et al, }{ }^{43} \text { Ding et al }{ }^{45}\end{array}$ \\
\hline $\begin{array}{l}\mathrm{HBsAg} \\
\text { (positive vs negative) }\end{array}$ & 12 & $0.83(0.67,1.03)$ & 1.67 & 0.094 & $94.20 \%$ & $<0.001$ & $\begin{array}{l}\text { Huang et al, }{ }^{11} \text { Yuan et al, }{ }^{15} \text { Wang et al, }{ }^{16} \text { Peng et al, }{ }^{17} \\
\text { Deng et al }{ }^{18} \mathrm{Hu} \text { et al, }{ }^{20} \text { Wang et al, }{ }^{22} \text { Xu et al, }{ }^{25} \\
\text { Shi et al, }{ }^{40} \text { Tu et al },^{41} \text { Ding et al, }{ }^{45} \text { Wang et al }{ }^{48}\end{array}$ \\
\hline $\begin{array}{l}\text { Microvascular } \\
\text { invasion } \\
\text { (yes vs no) }\end{array}$ & 10 & I.44 (I.10,I.89) & 2.62 & 0.009 & $69.60 \%$ & 0.001 & $\begin{array}{l}\text { Huang et al, }{ }^{11} \text { Yuan et al, }{ }^{15} \text { Peng et al, }{ }^{17} \text { Deng et al, }{ }^{18} \\
\text { Wang et al, }{ }^{22} \text { Li et al, }{ }^{23} \text { Yang et al, }{ }^{39} \text { Shi et al, }{ }^{40} \\
\text { Wang et al, }{ }^{47} \text { Wang et a }{ }^{48}\end{array}$ \\
\hline $\begin{array}{l}\text { PVTT } \\
\text { (yes vs no) }\end{array}$ & 5 & $1.50(1.03,2.20)$ & 2.1 & 0.036 & $0.00 \%$ & 0.428 & $\begin{array}{l}\text { Lai et al, },^{13} \text { Yang et al, },{ }^{14} \mathrm{Xu} \text { et al, }{ }^{25} \text { Zhang et al, }{ }^{38} \\
\text { Ding et a }{ }^{45}\end{array}$ \\
\hline
\end{tabular}

Notes: $P^{2}>50 \%$ with the random-effects model; $P^{2}<50 \%$ with the fixed-effects model (Mantel-Haenszel). $P<0.05$ was considered statistically significant.

Abbreviations: AFP, alfa-fetoprotein; $\mathrm{Cl}$, confidence interval; $\mathrm{HCC}$, hepatocellular carcinoma; HBsAg, hepatitis B virus surface antigen; IncRNA, long noncoding RNA; OR, odds ratio; TNM, tumor-node-metastasis; PVTT, portal vein tumor thrombosis.

treatments changed the overall result, while this result was not confirmed in meta-regression analysis. Considering that HCC patients enrolled in most articles were treated with hepatic resection, and only one article reported liver transplantation, we thus could not confirm the source of heterogeneity. In future, more studies that comprised different types of treatment for HCC should be included in meta-analysis to confirm whether treatment is a source of heterogeneity.
Only three studies showed the relationship between lncRNAs and DFS, although no significant association was found in DFS (HR: $1.39,95 \%$ CI: $0.51-3.78, P=0.524$ ); we could not draw a definite conclusion as more studies with large sample size are needed.

Moreover, we evaluated the correlation of IncRNA transcription level with the main clinicopathological parameters of HCC; subgroup analysis showed that lncRNA transcription 
level was only associated with tumor size $(>5 \mathrm{~cm}$ vs $\leq 5 \mathrm{~cm}$ : $\mathrm{RR}=1.19,95 \% \mathrm{CI}: 1.01-1.39, P=0.035)$, microvascular invasion (Yes vs No: $\mathrm{RR}=1.44,95 \% \mathrm{CI}: 1.10-1.89, P=0.009$ ), and portal vein tumor thrombus (Yes vs No: $\mathrm{RR}=1.5095 \% \mathrm{CI}$ : 1.03-2.20, $P=0.036)$. Previous studies have shown that AFP level, ${ }^{52}$ TNM stage, ${ }^{53}$ and histological differentiation ${ }^{54}$ were associated with an unfavorable outcome in HCC patients; however, no significant association was found between lncRNA transcription level and HBV infection (positive vs negative: $\mathrm{RR}=0.83$, 95\% CI: 0.67-1.03), cirrhosis (Yes vs No: RR $=0.94$, 95\% CI: 0.67-1.32), and TNM stage (III/IV vs I/II: RR $=1.11$, 95\% CI: 0.79-1.56), as well as AFP level, tumor number, and histological differentiation. One potential explanation for these differences might be that the number of included studies was relatively limited and just one study for each lncRNA in most cases; thus, the relationship between lncRNAs and clinicopathological features was underestimated.

Furthermore, only lncRNA GAS5 and PVT1 were reported twice in this meta-analysis, and the pooled HR of these two IncRNAs were 0.43 (95\% CI: $0.51-3.78, I^{2}=0.0 \%, P=0.865$ ) and 1.32 (95\% CI: $0.64-2.69, I^{2}=0.0 \%, P=0.443$ ) (Figure S4), which showed no prognostic value in HCC development. GAS5 exhibited tumor-suppressive activities in HCCs through negative regulation of miR-21 and proteins involved in regulating migration and invasion of cancer cells, like PTEN and vimentin. ${ }^{55}$ Furthermore, it also was an independent prognostic factor for patients with HCC. The diminished prognostic value in our study may be owing to the complicated network among lncRNA, miRNA, and proteins.

It should be emphasized that there are several limitations in our study. Firstly, because all the patients enrolled in the articles of this meta-analysis were Chinese, the results of this study cannot be extended to all populations; secondly, different lncRNAs were used to assess the prognosis of HCC, and there was a lack of specific HCC-related lncRNA for clinical evaluation; thirdly, since there was only one study for each lncRNA in most cases, the prognostic value of each lncRNA may be overestimated. What is more, unlike serum, detection of lncRNAs within tumor tissues makes it more difficult in clinical application. Finally, substantial heterogeneity was shown across the included studies.

In conclusion, the present results confirmed the strong prognostic value of IncRNA transcription level in HCC. However, in view of the limitation of studies about individual lncRNAs, in future, the prognostic value of different IncRNAs that detected in different populations are required to enroll for meta-analysis and thus confirm the clinical utility of lncRNAs in HCC prognosis evaluation.

\section{Acknowledgments}

This work was supported by the National Natural Science Foundation of China (No 81371897) and Hubei Province Health and Family Planning Scientific Research Project (WJ2015MB032). This work was also funded by “351 talent project (Luojia Young Scholars)" of Wuhan University.

\section{Disclosure}

The authors report no conflicts of interest in this work.

\section{References}

1. Wong KM, Yeh ML, Chuang SC, et al. Survival comparison between surgical resection and percutaneous radiofrequency ablation for patients in Barcelona Clinic Liver Cancer early stage hepatocellular carcinoma. Indian J Gastroenterol. 2013;32(4):253-257.

2. Colombo M, Sangiovanni A. Treatment of hepatocellular carcinoma: beyond international guidelines. Liver Int. 2015;35(suppl 1): 129-138.

3. Lin S, Hoffmann K, Schemmer P. Treatment of hepatocellular carcinoma: a systematic review. Liver Cancer. 2012;1(3-4):144-158.

4. Rich N, Singal AG. Hepatocellular carcinoma tumour markers: current role and expectations. Best Pract Res Clin Gastroenterol. 2014;28(5): 843-853.

5. Forones NM, Queiroz LA, Ferraz ML, Parise ER. Alphafetoprotein in hepatic tumours and benign liver diseases. Rev Assoc Med Bras. 1995; 41(2):91-93.

6. Chen DS, Sung JL. Serum alphafetoprotein in hepatocellular carcinoma. Cancer. 1977;40(2):779-783.

7. Yang X, Xie X, Xiao YF, et al. The emergence of long non-coding RNAs in the tumorigenesis of hepatocellular carcinoma. Cancer Lett. 2015; 360(2):119-124.

8. Tsai MC, Spitale RC, Chang HY. Long intergenic noncoding RNAs: new links in cancer progression. Cancer Res. 2011;71(1):3-7.

9. Huang MD, Chen WM, Qi FZ, et al. Long non-coding RNA TUG1 is up-regulated in hepatocellular carcinoma and promotes cell growth and apoptosis by epigenetically silencing of KLF2. Mol Cancer. 2015; $14: 165$.

10. Zhu J, Liu S, Ye F, et al. The long noncoding RNA expression profile of hepatocellular carcinoma identified by microarray analysis. PloS One. 2014;9(7):e101707.

11. Huang JF, Guo YJ, Zhao CX, et al. Hepatitis B virus X protein (HBx)related long noncoding RNA (lncRNA) down-regulated expression by $\mathrm{HBx}$ (Dreh) inhibits hepatocellular carcinoma metastasis by targeting the intermediate filament protein vimentin. Hepatology. 2013; 57(5):1882-1892.

12. Yuan JH, Yang F, Wang F, et al. A long noncoding RNA activated by TGF-beta promotes the invasion-metastasis cascade in hepatocellular carcinoma. Cancer Cell. 2014;25(5):666-681.

13. Lai MC, Yang Z, Zhou L, et al. Long non-coding RNA MALAT-1 overexpression predicts tumor recurrence of hepatocellular carcinoma after liver transplantation. Med Oncol. 2012;29(3):1810-1816.

14. Yang Z, Zhou L, Wu LM, et al. Overexpression of long non-coding RNA HOTAIR predicts tumor recurrence in hepatocellular carcinoma patients following liver transplantation. Ann Surg Oncol. 2011;18(5): 1243-1250.

15. Yuan SX, Yang F, Yang Y, et al. Long noncoding RNA associated with microvascular invasion in hepatocellular carcinoma promotes angiogenesis and serves as a predictor for hepatocellular carcinoma patients' poor recurrence-free survival after hepatectomy. Hepatology. 2012; 56(6):2231-2241.

16. Wang F, Ying HQ, He BS, et al. Upregulated lncRNA-UCA1 contributes to progression of hepatocellular carcinoma through inhibition of miR-216b and activation of FGFR1/ERK signaling pathway. Oncotarget. 2015;6(10):7899-7917. 
17. Peng W, Fan H. Long non-coding RNA PANDAR correlates with poor prognosis and promotes tumorigenesis in hepatocellular carcinoma. Biomed Pharmacother. 2015;72:113-118.

18. Deng L, Yang SB, Xu FF, Zhang JH. Long noncoding RNA CCAT1 promotes hepatocellular carcinoma progression by functioning as let-7 sponge. J Exp Clin Cancer Res. 2015;34:18.

19. Zhang J, Fan D, Jian Z, Chen GG, Lai PB. Cancer Specific Long Noncoding RNAs Show Differential Expression Patterns and Competing Endogenous RNA Potential in Hepatocellular Carcinoma. PloS One. 2015;10(10):e0141042.

20. Hu L, Ye H, Huang G, et al. Long noncoding RNA GAS5 suppresses the migration and invasion of hepatocellular carcinoma cells via miR-21. Tumour Biol. 2016;37(2):2691-2702.

21. Yuan SX, Wang J, Yang F, et al. Long noncoding RNA DANCR increases stemness features of hepatocellular carcinoma by derepression of CTNNB1. Hepatology. 2016;63(2):499-511.

22. Wang TH, Lin YS, Chen Y, et al. Long non-coding RNA AOC4P suppresses hepatocellular carcinoma metastasis by enhancing vimentin degradation and inhibiting epithelial-mesenchymal transition. Oncotarget. 2015;6(27):23342-23357.

23. Li T, Xie J, Shen C, et al. Upregulation of long noncoding RNA ZEB1-AS1 promotes tumor metastasis and predicts poor prognosis in hepatocellular carcinoma. Oncogene. 2016;35(12):1575-1584.

24. Geng YJ, Xie SL, Li Q, Ma J, Wang GY. Large intervening non-coding RNA HOTAIR is associated with hepatocellular carcinoma progression. J Int Med Res. 2011;39(6):2119-2128.

25. Xu WH, Zhang JB, Dang Z, et al. Long non-coding RNA URHC regulates cell proliferation and apoptosis via ZAK through the ERK/MAPK signaling pathway in hepatocellular carcinoma. Int J Biol Sci. 2014 10(7):664-676.

26. Zhang S, Chen S, Yang G, et al. Long noncoding RNA HOTAIR as an independent prognostic marker in cancer: a meta-analysis. PloS One. 2014;9(8):e105538.

27. Zhang J, Zhang B, Wang T, Wang H. LncRNA MALAT1 overexpression is an unfavorable prognostic factor in human cancer: evidence from a meta-analysis. Int J Clin Exp Med. 2015;8(4):5499-5505.

28. Cai B, Wu Z, Liao K, Zhang S. Long noncoding RNA HOTAIR can serve as a common molecular marker for lymph node metastasis: a meta-analysis. Tumour Biol. 2014;35(9):8445-8450.

29. Altman DG, McShane LM, Sauerbrei W, Taube SE. Reporting Recommendations for Tumor Marker Prognostic Studies (REMARK): explanation and elaboration. PLoS Med. 2012;9(5):e1001216.

30. McShane LM, Altman DG, Sauerbrei W, et al. REporting recommendations for tumor MARKer prognostic studies (REMARK). Nat Clin Pract Oncol. 2005;2(8):416-422.

31. Fan JL, Yang YF, Yuan CH, Chen H, Wang FB. Circulating tumor cells for predicting the prognostic of patients with hepatocellular carcinoma: a meta analysis. Cel Physiol Biochem. 2015;37(2):629-640.

32. Parmar MK, Torri V, Stewart L. Extracting summary statistics to perform meta-analyses of the published literature for survival endpoints. Stat Med. 1998;17(24):2815-2834.

33. Williamson PR, Smith CT, Hutton JL, Marson AG. Aggregate data meta-analysis with time-to-event outcomes. Stat Med. 2002;21(22): 3337-3351.

34. Tierney JF, Stewart LA, Ghersi D, Burdett S, Sydes MR. Practical methods for incorporating summary time-to-event data into meta-analysis. Trials. 2007;8:16.

35. Egger M, Davey Smith G, Schneider M, Minder C. Bias in meta-analysis detected by a simple, graphical test. BMJ. 1997;315(7109):629-634.

36. Shen J, Siegel AB, Remotti H, Wang Q, Shen Y, Santella RM. Exploration of deregulated long non-coding RNAs in association with hepatocarcinogenesis and survival. Cancers (Basel). 2015;7(3): 1847-1862.
37. Quagliata L, Matter MS, Piscuoglio S, et al. Long noncoding RNA HOTTIP/HOXA13 expression is associated with disease progression and predicts outcome in hepatocellular carcinoma patients. Hepatology. 2014;59(3):911-923.

38. Zhang T, Cao C, Wu D, Liu L. SNHG3 correlates with malignant status and poor prognosis in hepatocellular carcinoma. Tumour Biol. 2016;37(2):2379-2385.

39. Yang N, Fu Y, Zhang H, Sima H, Zhu N, Yang G. LincRNA-p21 activates endoplasmic reticulum stress and inhibits hepatocellular carcinoma. Oncotarget. 2015;6(29):28151-28163.

40. Shi XM, Teng F. Up-regulation of long non-coding RNA Sox2ot promotes hepatocellular carcinoma cell metastasis and correlates with poor prognosis. Int J Clin Exp Pathol. 2015;8(4):4008-4014.

41. Tu ZQ, Li RJ, Mei JZ, Li XH. Down-regulation of long non-coding RNA GAS5 is associated with the prognosis of hepatocellular carcinoma. Int J Clin Exp Pathol. 2014;7(7):4303-4309.

42. Zhou T, Gao Y. Increased expression of LncRNA BANCR and its prognostic significance in human hepatocellular carcinoma. World $J$ Surg Oncol. 2016;14(1):8.

43. Yan TH, Yang H, Jiang JH, et al. Prognostic significance of long noncoding RNA PCAT-1 expression in human hepatocellular carcinoma. Int J Clin Exp Pathol. 2015;8(4):4126-4131.

44. Ge Y, Yan X, Jin Y, et al. Correction: fMiRNA-192 and miRNA-204 directly suppress IncRNA HOTTIP and interrupt GLS1-mediated glutaminolysis in hepatocellular carcinoma. PLoS Genet. 2016;12(1): e1005825.

45. Ding C, Yang Z, Lv Z, et al. Long non-coding RNA PVT1 is associated with tumor progression and predicts recurrence in hepatocellular carcinoma patients. Oncol Lett. 2015;9(2):955-963.

46. Guo S, Chen W, Luo Y, et al. Clinical implication of long non-coding RNA NEAT1 expression in hepatocellular carcinoma patients. Int $J$ Clin Exp Pathol. 2015;8(5):5395-5402.

47. Wang F, Xie C, Zhao W, Deng Z, Yang H, Fang Q. Long non-coding RNA CARLo-5 expression is associated with disease progression and predicts outcome in hepatocellular carcinoma patients. Clin Exp Med. 2015:1-11.

48. Wang F, Yuan JH, Wang SB, et al. Oncofetal long noncoding RNA PVT1 promotes proliferation and stem cell-like property of hepatocellular carcinoma cells by stabilizing NOP2. Hepatology. 2014;60(4): $1278-1290$

49. Hua L, Wang CY, Yao KH, Chen JT, Zhang JJ, Ma WL. High expression of long non-coding RNA ANRIL is associated with poor prognosis in hepatocellular carcinoma. Int J Clin Exp Pathol. 2015;8(3): 3076-3082.

50. Yang F, Zhang L, Huo XS, et al. Long noncoding RNA high expression in hepatocellular carcinoma facilitates tumor growth through enhancer of zeste homolog 2 in humans. Hepatology. 2011;54(5):1679-1689.

51. Zhang H, Chen Z, Wang X, Huang Z, He Z, Chen Y. Long non-coding RNA: a new player in cancer. J Hematol Oncol. 2013;6:37.

52. Nomura F, Ohnishi K, Tanabe Y. Clinical features and prognosis of hepatocellular carcinoma with reference to serum alpha-fetoprotein levels. Analysis of 606 patients. Cancer. 1989;64(8):1700-1707.

53. Liu C, Duan LG, Lu WS, et al. Prognosis evaluation in patients with hepatocellular carcinoma after hepatectomy: comparison of BCLC, TNM and Hangzhou criteria staging systems. PloS One. 2014;9(8): e103228.

54. Enomoto S, Tamai H, Shingaki N, et al. Assessment of hepatocellular carcinomas using conventional magnetic resonance imaging correlated with histological differentiation and a serum marker of poor prognosis. Hepatol Int. 2011;5(2):730-737.

55. Hu L, Ye H, Huang G, et al. Long noncoding RNA GAS5 suppresses the migration and invasion of hepatocellular carcinoma cells via miR-21. Tumour Biol. 2016;37(2):2691-2702. 


\section{Publish your work in this journal}

OncoTargets and Therapy is an international, peer-reviewed, open access journal focusing on the pathological basis of all cancers, potential targets for therapy and treatment protocols employed to improve the management of cancer patients. The journal also focuses on the impact of management programs and new therapeutic agents and protocols on

patient perspectives such as quality of life, adherence and satisfaction. The manuscript management system is completely online and includes a very quick and fair peer-review system, which is all easy to use. Visit http://www.dovepress.com/testimonials.php to read real quotes from published authors.

Submit your manuscript here: http://www.dovepress.com/oncotargets-and-therapy-journal 